4144. Melanotus Leonardi Lec.

This is thought to be the first instance of the capture of this species in Massachusetts. Leconte records it (Trans. Amer. Phil. Soc., Vol. X, new series, p. 475) from New Hampshire, Georgia, and Pennsylvania. A closely allied species was collected by Mr. Austin upon alders in the vicinity of Mt. Tom (M. tcenicollis Lec.) described from Philadelphia, which is thought to be new to the fauna of New England.

4163. Melanotus americanus Hbst.
4187. Limonius confusus Lec.(onescens Lec.)

4193. Limonius quercinus Say.

4197. " basillaris Say.

Of the last two species the former has generally been found to be very abundant and the other quite rare, but this year (1873) basillaris has been the more abundant of the two.

4253. Sericosomus silaceus Say.

4308. Corymbites. medianus Germ.

$4313 . \quad$ " hieroglyphicus Say. 4325. " metallicus Payk. (nitidulus Lec)

4326. Corymbites inflatus Say.

Samuel Henshaw.

\title{
Early Spring Butterflies at the White Mountains.
}

(Continued from page 14.)

Limnoecia Harrisii. Last autumn I found the young caterpillars swarming upon Diplopappus umbellatus, at several points on the Glen road; in other places on the same road where Diplopappus grew, none could be found. This spring they were found in precisely the same localities as last autumn, and were absent from the others, proving that they must hibernate in close proximity to their birth place. They hibernate in their penultimate stage, probably in curled up dead leaves, and though several may be found on one plant in the spring, they do not then associate nor spin a web; when about to moult, the caterpillars leave the plant and retire to a dead stick or leaf for the change, and then return to their pasture ground. They were also found in great numbers on Diplopappus growing on the hill side beyond the foot bridge over the Androscoggin at Gorham. The first to change to chrysalis did so June 6th and emerged June 19th.

Euphydryas Phaeton. The caterpillars were found in considerable numbers in just as advanced a stage as those of the previous species, upon Lonicera ciliata; as they were found only upon this plant, and in many different places, this is doubtless its proper spring food; they fed in confinement on other species of Lonicera. The first butterfly emerged June 25th, after $17 \frac{1}{2}$ days in chrysalis. Not a single caterpillar of this or the preceding species or of Arthemis was found to be parasitized. 
Cyaniris Lucia. Hundreds were seen every day, though no females were seen the first day, and but very few at all; they were easily taken with the fingers. The female was noticed in two or three instances, on the 5th, hovering about a particular species of plant by the roadside; this was brought away for identification, but unfortunately lost.

Ganoris rapce. Both sexes plenty and fresh, but almost exclusively confined to the neighborhood of houses or the high road, in contradistinction to the habits of the next species.

Ganoris oleracea. A few fresh specimens of both sexes were taken; the butterfly seemed to confine its wanderings to open places in the woods and to forsaken roads through them, seldom occurring in the same haunts with the last species.

Euphoeades Glaucus. Two or three specimens were seen on the 5th, none before; this day was much warmer than any of the previous, and doubtless was their birth-day.

Erynnis Icelus. A single specimen was seen on the 2d; three or four scen and captured on the $3 \mathrm{~d}$, all males; on the 4 th they were common and a single female taken; on the 5th nearly a hundred were seen and several of those captured were females.

S. H. Scudder.

\section{BIBLIOGRAPHICAL RECORD.}

Authors and Societies are requested to forward their works to the Editor at the earliest date possible. We ask our readers to inform us of the publication especially of those works which are not generally consulted by entomologists.

B. Pickman Mann.

(Continued from page 16.)

* 34. B. P. ManN. A remedy for the Currant Worm and the Hop Louse. No. 19 (1683).

Nematus ventricosus, Ellopia ribearia, Aphis humuli.

* 35. L. S. Richards. The Worm and the Ant. No. 26 (1691).

Habitations, colonies, habits and wars of ants.

* 36. Enitor. Cranberry Culture. No 37 (1701).

Habits of the vine worm (Anchylopera vacciniana) and the fruit worm (Tortrix? sp?).

* 37. Western Farmer. The Plum Curculio. No. 37 (1701).

Description?; habits; means against them. 

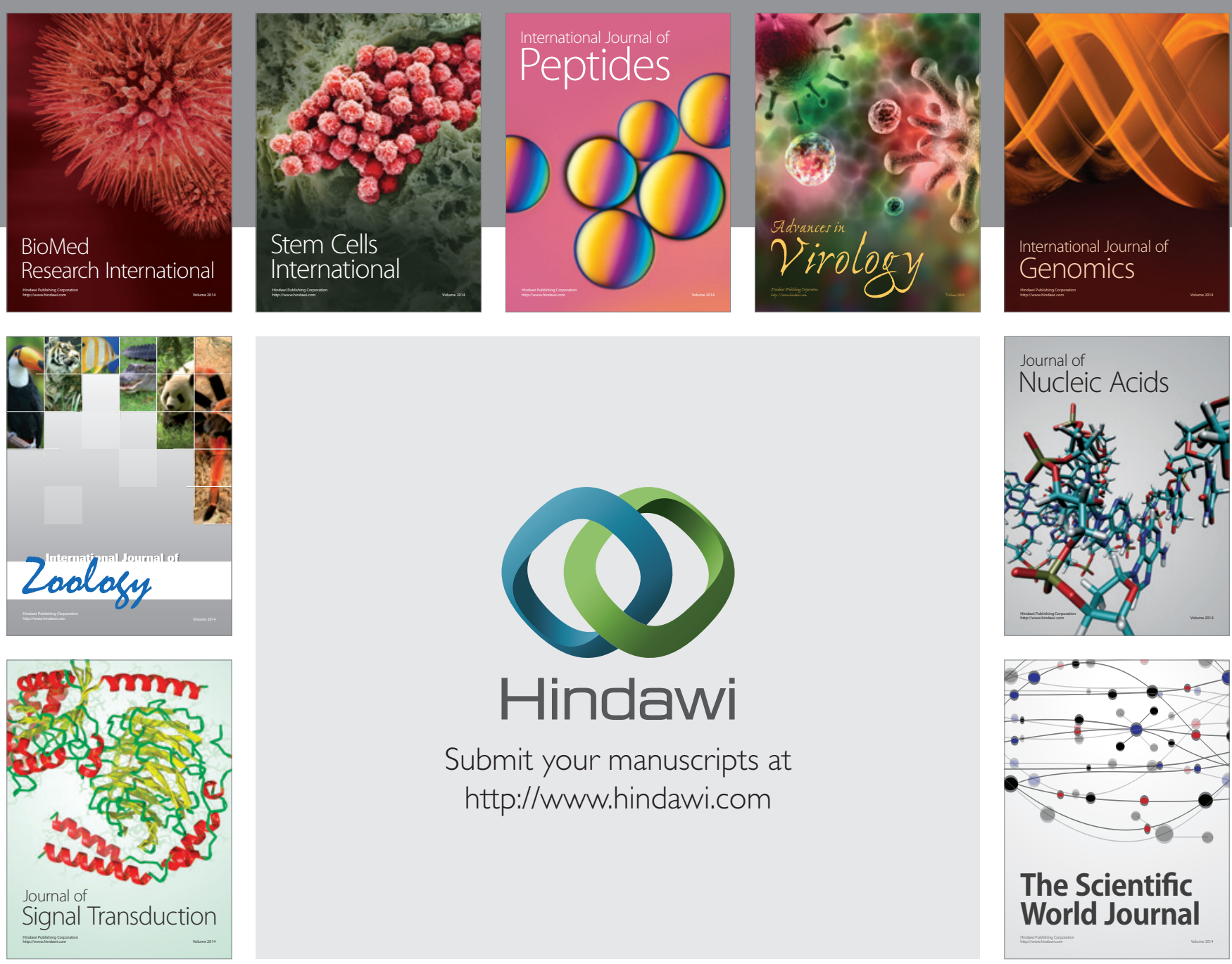

Submit your manuscripts at

http://www.hindawi.com
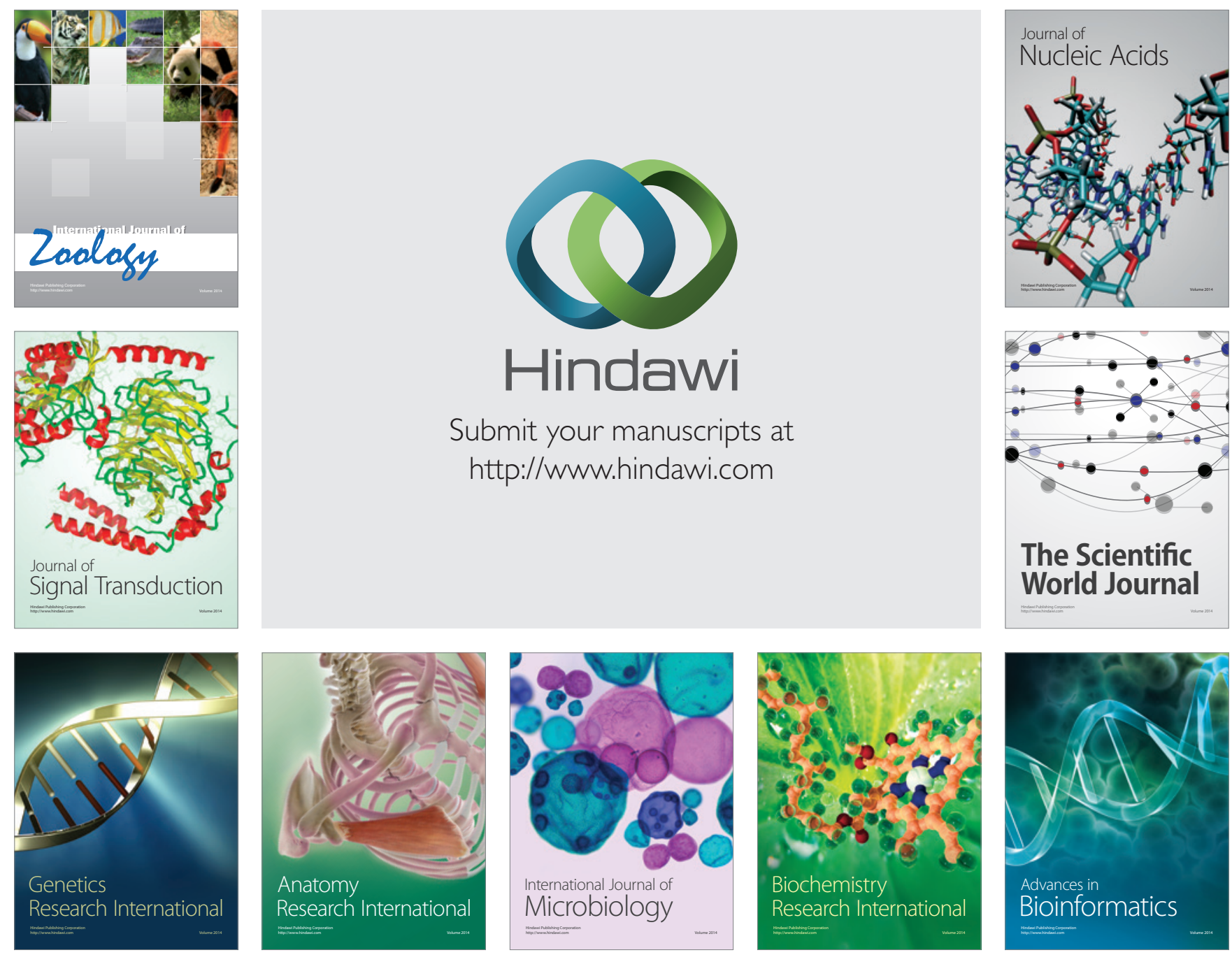

The Scientific World Journal
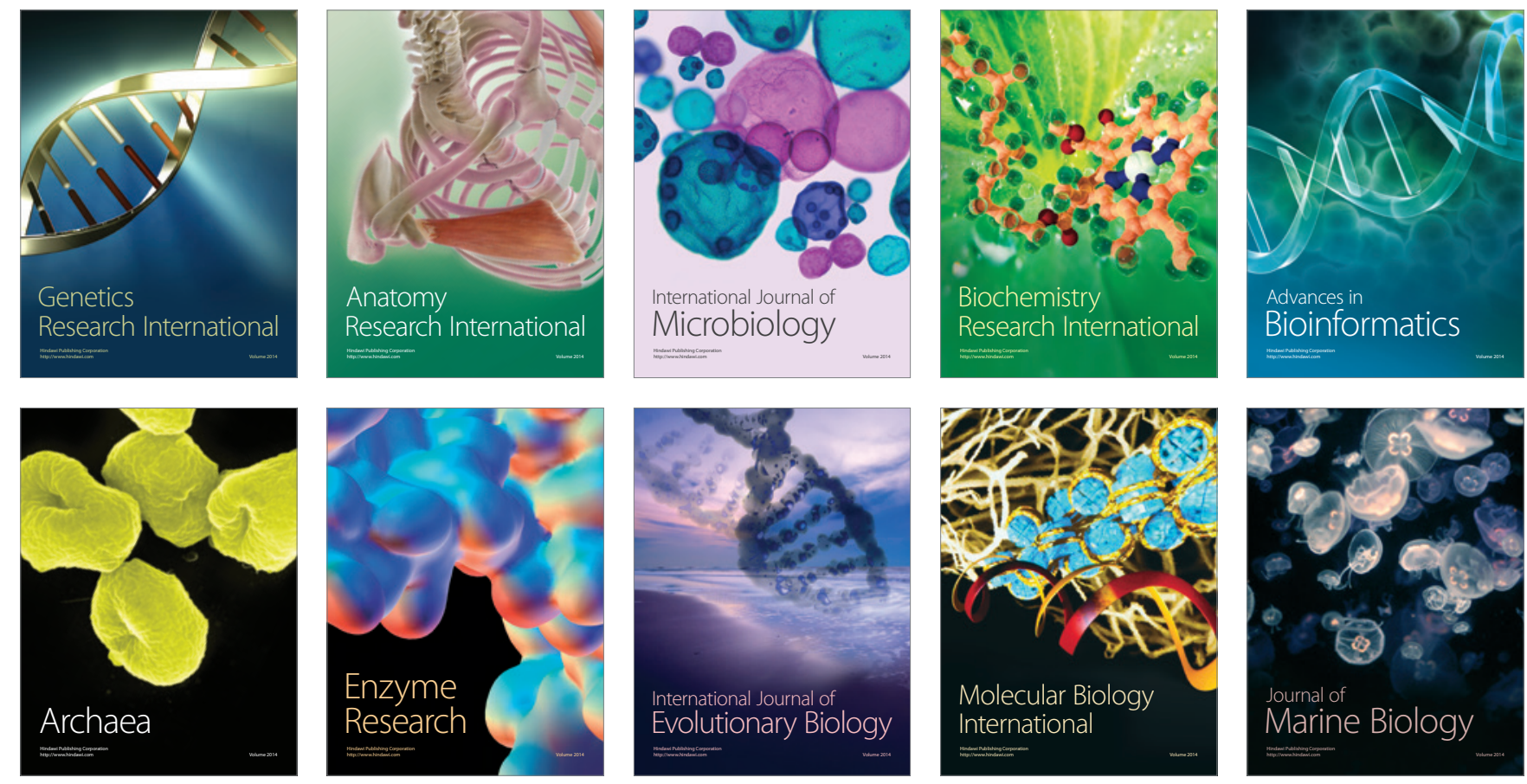